\title{
Ricci solitons of the Sol3 Lie group
}

\author{
BELARBI LAKEHAL ${ }^{1}$ \\ ${ }^{1}$ Universite Abdelhamid Ibn Badis de Mostaganem
}

July 26, 2020

\begin{abstract}
In this work we consider the three-dimensional solvable Lie group denoted by $\$$ Sol_ $\{3\} \$$, equipped with any left-invariant metric, either Lorentzian or Riemannian. The existence of non-trivial (i.e., not Einstein) Ricci solitons on both Lorentzian and Riemannian three-dimensional solvable Lie group $\$ \operatorname{Sol}_{-}\{3\} \$$ is proved. Moreover, we show that they are not gradient Ricci solitons.
\end{abstract}

\section{Hosted file}

Ricci solitons of the Sol3 group.pdf available at https://authorea.com/users/222613/articles/ 472309-ricci-solitons-of-the-sol3-lie-group 